\title{
PROTEINORRAQUIA. ESTUDO CRfTICO DE MÉTODOS DE DOSAGEM
}

\author{
A. SPINA FRANÇA NET'TO* F. M. DA CUNHA CERQUEIRA * \\ ISAAC AMAR **
}

Mestrezat 18, em 1912, numa das primeiras revisões sôbre a dosagem de proteínas no líqüido cefalorraquidiano (LCR), já considerava o método de Kjeldahl como um dos mais precisos, embora de aplicação prática limitada; aconselhava, para uso de rotina, o método gravimétrico baseado na precipitação de proteinas pelo ácido tricloroacético e o método de Nissl. Êste, segundo Mestrezat, foi proposto em 1904 e se baseia na precipitação das proteínas pelo reativo de Esbach e leitura, após centrifugação, do volume do precipitado, cuja correlação com a concentração foi estabelecida em 1907 por Nonne e Appelt. Apesar da precisão limitada, seu emprêgo é ainda muito difundido. Empregando processo semelhante ao de Nissl e o mesmo reativo, Kafka ${ }^{14}$ estabeleceu novo método, de precisão maior em virtude do tipo de tubos e de padrão usados.

Além dêsses, vários métodos têm sido propostos, na maioria limitados a certos centros, destacando-se alguns, de emprêgo mais difundido. Entre êstes se coloca o de Denis e Ayer ${ }^{1 \bar{i}}$, que tem sofrido várias modificaçōes, como as de Ayer, Dailey e Fremont-Smith ${ }^{2}$ e de Cipriani e Brophy ${ }^{7}$; baseia-se na análise turbidimétrica do material tratado pelo ácido sulfossalicílico. Em 1937, Merritt e Fremont-Smith ${ }^{1 ;}$ consideravam-no como o que fornecia resultados mais próximos do real; sua segurança, entretanto, tem sido posta em dúvida e Bauer e Angelstein 3, num estudo. comparativo entre três métodos, concluíram ser êle o menos preciso; todavia, sua utilização continua a ser preconizada (Wawersick e Boeckler ${ }^{21}$ ). Mais recentemente, Bossak, Rosenberg e Harris ${ }^{5}$ desenvolveram método turbidimétrico baseado na precipitação das proteínas pelo ácido tricloroacético, tendo demonstrado ser menos sensivel a variações das taxas relativas de albumina e globulinas que o anterior; Harding e Harris ${ }^{12}$ aperfeiçoaram êste método.

Várias técnicas colorimétricas têm sido também desenvolvidas, como a de Machebœuf e Rebeyrotte ${ }^{11}$, operando com o ácido nítrico e a de Dittebrandt 9 , com o reativo do biureto de Weichselbaum.

Trabalho da Secção de Líqüido Cefalorraquidiano do Laboratório Central do Hospital das Clinicas da Faculdade de Medicina da Univ. de São Paulo (Serviço do Dr. O. A. Germek), apresentado no XIX Congresso Internacional de Oto-Neuro-oftalmologia (São Paulo, junho de 1954).

* Médicos auxiliares.

* * Acadêmico estagiário. 
Os registros da literatura assinalam padrões de normalidade diversos, por vêzes variando entre limites muito grandes, obtidos por métodos diferentes de dosagem. Assim, Andía ${ }^{1}$ estabelece como normal a taxa de $28 \mathrm{mg}$ por $100 \mathrm{ml}$; para Bonola ${ }^{4}$ os limites normais estão entre 10 e 15; para Cantani ${ }^{6}$, vão até 20; para Demme ${ }^{8}$, variam entre 19 e 28; para Eskuchen ${ }^{10}$, entre 20 e 25; para Kafka ${ }^{14}$, entre 10 e 30; para Lange ${ }^{15}$, entre 10 e 20; para Levinson ${ }^{16}$, entre 13 e 47; para Fiessinger, Olivier e Herbain ${ }^{11}$, em tôrno de 20; para Merritt e Fremont-Smith ${ }^{17}$, entre 15 e 45; para Mestrezat ${ }^{18}$, entre 13 e $30 \mathrm{mg}$ por $100 \mathrm{ml}$. Isto, assim mesmo, sem considerar o nível de colheita e as variações etárias.

Vários estudos comparativos entre métodos têm sido efetuados tendo como finalidade principal explorar a precisão relativa de cada um; assim, Bauer e Angelstein ${ }^{3}$, que compararam os de Kafka, do biureto e do ácido sulfossalicílico, dão mais crédito ao primeiro; Sandmann ${ }^{20}$, comparando o método de Gleiss e Hinsberg (fotométrico) com o de Kafka, encontrou maior sensibilidade naquele; Wikoff e Kazdan ${ }^{22}$ verificaram sensibilidade semelhante nos métodos de Johnston e Gibson (ácido tricloroacético a 20\%), de Matz e Novick (reativo de tungstato de sódio e ácido sulfúrico) e o de Denis e Ayer, todos turbidimétricos.

Com a finalidade de explorar até que ponto as particularidades de cada método influenciam sôbre as variações das taxas consideradas normais, foi efetuado o presente estudo, utilizando os métodos de Denis e Ayer, Bossak e col., Machebœuf e Rebeyrotte e de Dittebrandt.

\section{MATERIAL E METODOS}

Foram utilizadas amostras de LCR obtidas de pacientes internados na Clínica: Neurológica do Hospltal das Clínicas da Fac. Med. da Univ. de São Paulo, examinadas, de preferência, no mesmo dia da colheita. Quando isto não era possivel, eram mantidas em congelador até a ocasião oportuna. As amostras só foram utilizadas quando limpidas e incolores e sempre após centrifugação.

Inicialmente foram constituídas três misturas ("pools"), de aproximadamente 500 $\mathrm{ml}$ cada uma, de líquores provenientes de cêrca de 100 pacientes, sendo determinadas suas taxas de nitrogênio total pelo método macro-Kjeldahl, segundo a técnica de Hiller, Plazin e van Slyke ${ }^{13}$; para cada "pool" foram feitas dosagens em duplicata, empregando, de cada vez, $100 \mathrm{ml}$ de LCR com a finalidade de evitar o êrro determinado pela pequena concentração protêica habitualmente encontrada no liquor. A taxa de nitrogênio protêico foi obtida pela diferença entre a taxa de nitrogênio total e a de nitrogênio não protêico, esta última determinada pelo micro-Kjeldahl, segundo a técnica dos mesmos autores ${ }^{13}$. A concentração protêica de cada "pool" foi, então, calculada pela multiplicação da taxa de nitrogênio protêico pelo fator 6,25 (taxa protêica $=\mathrm{N}$ protéico $\times 6,25)$.

A partir dessas amostras foram cuidadosamente preparadas diluições, as quais foram submetidas a análise pelos 4 métodos em estudo: de Bossak e col, de Denis e Ayer, de Dittebrandt e de Machebœuf e Rebeyrotte. Os dois primeiros são turbidimétricos e os últimos, colorimétricos; a leitura dos resultados foi efetuada em espectrofotômetro Coleman Junior, modêlo 6-A, no comprimento de onda preconizado para cada um dêsses métodos: 420 milimicra para o de Bossak e col.; 555 para o de para o de Dittebrandt; 420 para o de Denis e Ayer; 425 para o de Machebœuf e Rebeyrotte. Para os dois últimos foi feita exploração prévia usando cubas 6-304. A transmitância registrada para cada uma das diluições, cuja concentração era conhe- 
cida, foi lançada em papel semilogaritmico contra a concentração conhecida, sendo, assim, estabelecidas as respectivas cartas de calibração.

Certo número de amostras de LCR cuja taxa de proteínas fôra prèviamente avaliada pelo método de Nissl foram analisadas para cada um dos métodos em estudo e a concentração calculada pela carta de calibração respectiva. Em 20 amostras foram feitas determinaçôes concomitantes pelos 4 métodos acima citados e pelo de Nissl. Uma mesma amostra foi submetida a 5 determinações sucessivas para cada método, a fim de se calcular o desvio médio padrão.

\section{RESULTADOS E COMENTÁRIOS}

Dos três "pools" de LCR onde foi determinada a taxa de proteínas totais pelo método de Kjeldahl, dois apresentavam teor protêico pequeno e um, elevado; os resultados foram, respectivamente, 24,37 e $184,5 \mathrm{mg}$ por $100 \mathrm{ml}$. As curvas de calibração de cada um dos métodos, obtidas pela tomada de vários pontos, correspondentes à diluição dêsse material, estão representadas no gráfico 1 .

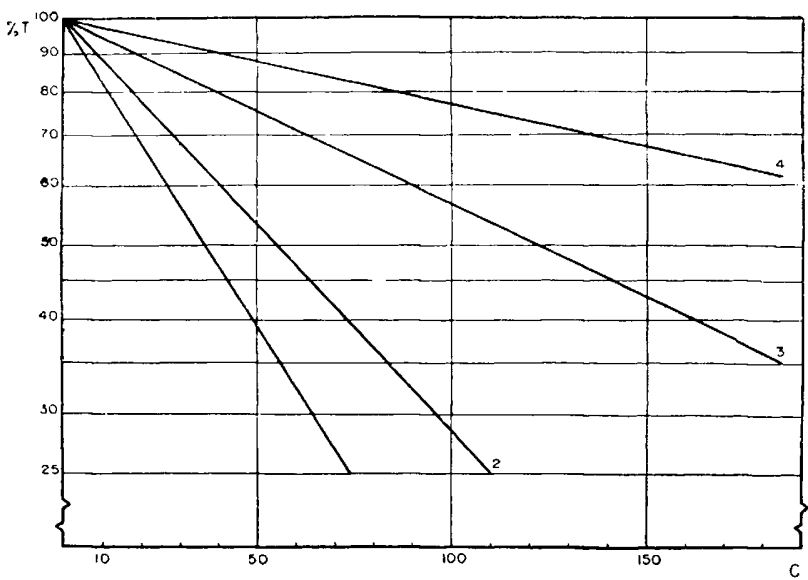

Gráfico 1 - Curvas de calibração obtidas para cada método na porção em que obedecem à equação da reta. $\mathrm{T}=$ $=$ transmitância; $\mathrm{C}=$ = concentração (mg/ $100 \mathrm{ml}$ ) 1 - método de Bossak e col.; 2 método de Denis e Ayer; 3 - método de Machebœuf e Rebeyrotte; 4 - método de Dittebrandt.

A análise das curvas obtidas mostrou obediência à equação da reta até a transmitância de $25 \%$ nos dois métodos turbidimétricos e até o máximo analisado, para os colorimétricos (35\% para o método de Machebœuf e Rebeyrotte e $62 \%$ para o de Dittebrandt), correspondendo a tais transmitâncias as concentrações assinaladas no quadro 1 .

\begin{tabular}{|c|c|}
\hline Mét odo & $\begin{array}{c}\text { Concentraçã o } \\
(\mathrm{mg} / 100 \mathrm{ml})\end{array}$ \\
\hline Bossak e col. .......... & 74,5 \\
\hline Denis e Ayer $\ldots \ldots \ldots \ldots \ldots \ldots$ & 110,0 \\
\hline Machebœuf e Rebeyrotte $\ldots . .$. & 184,5 \\
\hline Dittebrandt $* \ldots \ldots \ldots \ldots \ldots$ & 184,5 \\
\hline
\end{tabular}

Quadro 1 - Concentrações correspondentes ao limite de transmitância que obedecia à equação da reta nas curvas de calibração. *Valor máximo explorado. 
Para o espectrofotômetro tipo Coleman Junior, as medidas da transmitância apresentam fidelidade entre 5 e $90 \%$, embora o êrro instrumental efetivo já seja maior a partir de $80 \%$. A limitação decorrente corresponde a taxas baixas para os dois métodos turbidimétricos, médias para o de Machebœuf e Rebeyrotte e elevadas para o de Dittebrandt (quadro 2).

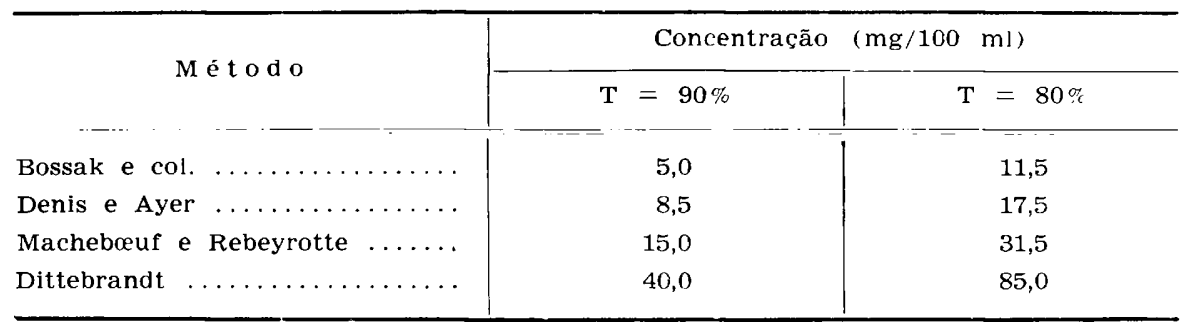

Quadro 2 - Valores de concentração correspondentes às transmitâncias de 80 e $90 \%$.

Os valores conceituados como normais para a proteinorraquia, variando de autor para autor, tornam difícil o estabelecimento de um número médio; mesmo assim, tomando como média a concentração de $20 \mathrm{mg}$ por $100 \mathrm{ml}$, apesar de a maioria das amostras analisadas proceder de colheita cisternal (punção suboccipital) onde o teor protêico é menor que no líquor lombar, ao qual correspondem a maioria dos valores registrados na literatura. A uma concentração de $20 \mathrm{mg}$ por $100 \mathrm{ml}$ corresponde uma transmitância inferior a $80 \%$ apenas nos dois métodos turbidimétricos estudados; dos colorimétricos, é inferior a $90 \%$ apenas para o de Machebœuf e Rebeyrotte.

As amostras cujas taxas protêicas foram avaliadas pelo método de Nissl e determinadas por um dos métodos em estudo estão grupadas no quadro 3 , segundo a transmitância registrada. Pela análise dêsse quadro se verifica em relação às taxas de 10 e $15 \mathrm{mg}$ (Nissl) que em nenhuma ocasião a transmitância correspondente foi igual ou maior a $90 \%$ pelo método de Bossak e col. (69 amostras); em 3, de 63 amostras, pelo método de Denis e Ayer; em 13, de 69, pelo de Machebœuf e Rebeyrotte e em 35, de 62, pelo de Dittebrandt. Isto vem mostrar a pequena fidelidade dos últimos métodos na determinação da proteinorraquia normal, pelo êrro instrumental efetivo introduzido. Como êste êrro existe também para transmitâncias entre 80 e $90 \%$, embora em menor grau, fica evidente a pequena fidelidade dos métodos colorimétricos estudados, já que a maioria das amostras analisadas por êles apresentou transmitância acima de $80 \%$ (quadro 4).

A mesma análise mostra a maior segurança oferecida pelo método de Bossak e col. em relação ao de Denis e Ayer, bem como sugere uma explicação para a discordância entre os valores propostos como normais por diversos autores, uma vez que se pode observar uma tendência à elevação da concentração média de cada grupo, proporcional ao aumento do número de 
amostras sujeitas a êrro instrumental efetivo grande (transmitância maior ou igual a $90 \%$ ).

\begin{tabular}{|c|c|c|c|c|c|c|c|c|}
\hline \multirow{2}{*}{ Mé to do } & \multirow{2}{*}{ Niss 1} & \multicolumn{5}{|c|}{ Transmitância } & \multirow{2}{*}{$\begin{array}{l}\text { No de } \\
\text { casos }\end{array}$} & \multirow{2}{*}{$\begin{array}{l}\text { Concen- } \\
\text { traçāo } \\
\text { média }\end{array}$} \\
\hline & & 60 & $\begin{array}{l}60 \mathrm{a} \\
69,5\end{array}$ & $\begin{array}{l}70 \mathrm{a} \\
79,5\end{array}$ & $\begin{array}{l}80 \mathrm{a} \\
89,5\end{array}$ & 90 & & \\
\hline \multirow{4}{*}{$\begin{array}{c}\text { Bossak e col. } \\
\text { (91) }\end{array}$} & 10 & 4 & 14 & 26 & 3 & - & 47 & 18,0 \\
\hline & 15 & - & 16 & 6 & - & - & 22 & 20,5 \\
\hline & 20 & 5 & 6 & 4 & - & - & 15 & 25,5 \\
\hline & 30 & 6 & - & 1 & - & - & 7 & 39,5 \\
\hline \multirow{4}{*}{$\begin{array}{c}\text { Denis e Ayer } \\
\text { (88) }\end{array}$} & 10 & - & 1 & 11 & 33 & 3 & 50 & 17,0 \\
\hline & 15 & 1 & - & 7 & 5 & - & 13 & 24,0 \\
\hline & 20 & 1 & 5 & 10 & 6 & - & 22 & 27,0 \\
\hline & 30 & 1 & 1 & 1 & - & 一 & 3 & 39,0 \\
\hline \multirow{4}{*}{$\begin{array}{l}\text { Machebœuf e } \\
\text { Rebeyrotte } \\
\text { (93) }\end{array}$} & 10 & - & 2 & 3 & 38 & 12 & 55 & 24,0 \\
\hline & 15 & - & - & 7 & 6 & 1 & 14 & 29,0 \\
\hline & 20 & - & - & 14 & 5 & 一 & 19 & 85,0 \\
\hline & 30 & 1 & 3 & - & - & 1 & 5 & 51,5 \\
\hline \multirow{4}{*}{$\begin{array}{l}\text { Dittebrandt } \\
\text { (81) }\end{array}$} & 10 & - & - & - & 19 & 31 & 50 & 40,0 \\
\hline & 15 & - & - & 1 & 7 & 4 & 12 & 43,5 \\
\hline & 20 & - & - & 3 & 6 & 7 & 16 & 54,5 \\
\hline & 30 & - & - & - & 3 & - & 3 & 71,5 \\
\hline
\end{tabular}

Quadro 3 - Distribuição de certo número de amostras segundo a transmitância registrada e conforme a concentraçâo avaliada (Nissl). A concentração média corresponde à média dos valores de concentração dessas amostras, obtidos a partir da carta de calibração do método. O número entre parênteses corresponde ao total de amostras analisadas pelo método. Valores de concentração em $\mathrm{mg} / 100 \mathrm{ml}$.

\begin{tabular}{lr|r}
\hline \multicolumn{2}{c|}{ M é t o d o } & \\
\hline \hline Bossak e col. & $(69) \ldots$ & 4,34 \\
Denis e Ayer & $(63) \ldots$ & 68,25 \\
Machebœuf e Rebeyrotte & $(69) \ldots$ & 82,60 \\
Dittebrandt & $(62) \ldots$ & 98,38 \\
\hline
\end{tabular}

Quadro 4 - Percentual de amostras cuja transmitância foi maior ou igual a $80 \% \mathrm{em}$ relação ao número total de amostras consideradas, colocado entre parênteses, e cujo teor protêico (10 a $15 \mathrm{mg}$ por $100 \mathrm{ml}$ ) fôra avaliado pelo método de Nissl.

Esse fato é bem ilustrado por uma série de 20 amostras cujo teor protêico fôra avaliado pelo método de Nissl em tôrno de $10 \mathrm{mg}$ por $100 \mathrm{ml}$, nas 
quais foi efetuada a determinação da proteinorraquia pelos quatro métodos. Os resultados (quadro 5) mostram um aumento da média das concentrações encontradas concomitante ao aumento do êrro instrumental efetivo introduzido pela transmitância mais elevada correspondente.

\begin{tabular}{|c|c|c|c|c|}
\hline \multirow{2}{*}{ Amostra } & \multicolumn{4}{|c|}{$\mathrm{M}$ é $\mathrm{t} \quad \mathrm{o} d \mathrm{o}$} \\
\hline & Bossak e col. & Denis e Ayer & $\begin{array}{c}\text { Machebcuf e } \\
\text { Rebcyrotte }\end{array}$ & Dittebrandt \\
\hline 1 & 18,0 & 21,5 & 28,5 & 45,0 \\
\hline 2 & 14,5 & 14,5 & 26,5 & 36,5 \\
\hline 3 & 14,5 & 15,5 & 30,0 & $4 \mathrm{C}, 0$ \\
\hline 4 & 13,0 & 16,5 & 15,0 & 36,5 \\
\hline 5 & 22,0 & 26,0 & $3 C, 0$ & 40,0 \\
\hline 6 & 13,0 & 10,0 & 15,0 & 27,0 \\
\hline 7 & 14,5 & 13,5 & 21,5 & 31,5 \\
\hline 8 & 16,5 & 14,5 & 20,0 & 45,0 \\
\hline 9 & 22,0 & 19,5 & 25,0 & 49,0 \\
\hline 10 & 26,5 & 23,5 & 33,5 & 58,0 \\
\hline 11 & 22,0 & 22,5 & 23,5 & 49,0 \\
\hline 12 & 16,5 & 12,5 & 18,5 & $4 C, 0$ \\
\hline 13 & 16,5 & 17,5 & 26,0 & 45,0 \\
\hline 14 & 17,5 & 13,5 & 25,0 & 45,0 \\
\hline 15 & 14,5 & 12,5 & 23,5 & 40,0 \\
\hline 16 & 21,0 & 16,5 & 21,5 & 49,0 \\
\hline 17 & 13,0 & 22,5 & 26,5 & 49,0 \\
\hline 18 & 9,0 & 18,5 & 21,5 & 49,0 \\
\hline 19 & 7,0 & 13,5 & 18,5 & 49,0 \\
\hline 20 & 9,5 & 14,5 & 21,5 & 45,0 \\
\hline Média & 16,0 & 17,0 & 22,5 & 43,5 \\
\hline$r: T$ & 74,0 & 80,0 & 85,5 & 89,5 \\
\hline
\end{tabular}

Quadro 5 - Amostras cujas taxas protêicas foram determinadas concomitantemente pelos quatro métodos; tôdas tinham sido avaliadas pelo método de Nissl como contendo $10 \mathrm{mg} / 100 \mathrm{ml}$ de proteínas. Média = média aritmética das dosagens; $\% \mathrm{~T}=$ transmitância correspondente a essa média. Valores de concentração em $\mathrm{mg} / 100 \mathrm{ml}$.

A análise de um lote grande de amostras vem corroborar o fato e sugerir valores médios mais elevados para os métodos nos quais o êrro instrumental efetivo influi de modo mais freqüente. No quadro 6, amostras assim analisadas permitem verificar o deslocamento que sofre o valor de concentração a que corresponde maior número de amostras e o gráfico 2, calcado nesse quadro, ilustra o fato. 


\begin{tabular}{|c|c|c|c|c|}
\hline \multirow{2}{*}{$\begin{array}{c}\text { Concentracão } \\
(\mathrm{mg} / 100 \mathrm{ml})\end{array}$} & \multicolumn{4}{|c|}{$M$ é $t \quad o d o$} \\
\hline & $\begin{array}{l}\text { Bossak e } \\
\text { col. }\end{array}$ & $\begin{array}{c}\text { Denis e } \\
\text { Ayer }\end{array}$ & $\begin{array}{l}\text { Machebœuf } \\
\text { e Rebcyrotte }\end{array}$ & Dittebrandi \\
\hline $0-9,5$ & - & 5 & 2 & - \\
\hline $10-19,5$ & 48 & 53 & 20 & 7 \\
\hline $20-29,5$ & 30 & 24 & 34 & 19 \\
\hline $30-39,5$ & 11 & 9 & 25 & 15 \\
\hline $40-49,5$ & 7 & 3 & 7 & 22 \\
\hline $50-59,5$ & 2 & 3 & 2 & 7 \\
\hline $60-69,5$ & - & 2 & 3 & 10 \\
\hline $70-79,5$ & - & 2 & 1 & 9 \\
\hline $80-89,5$ & - & - & - & 5 \\
\hline $90-99,5$ & - & $\ldots$ & - & 2 \\
\hline 100 & - & - & - & 2 \\
\hline Total de amostras & 98 & 101 & 94 & 98 \\
\hline
\end{tabular}

Quadro 6 - Freqüência dos valores correspondentes a cada concentração, em lotes diversos de amostras analisadas.

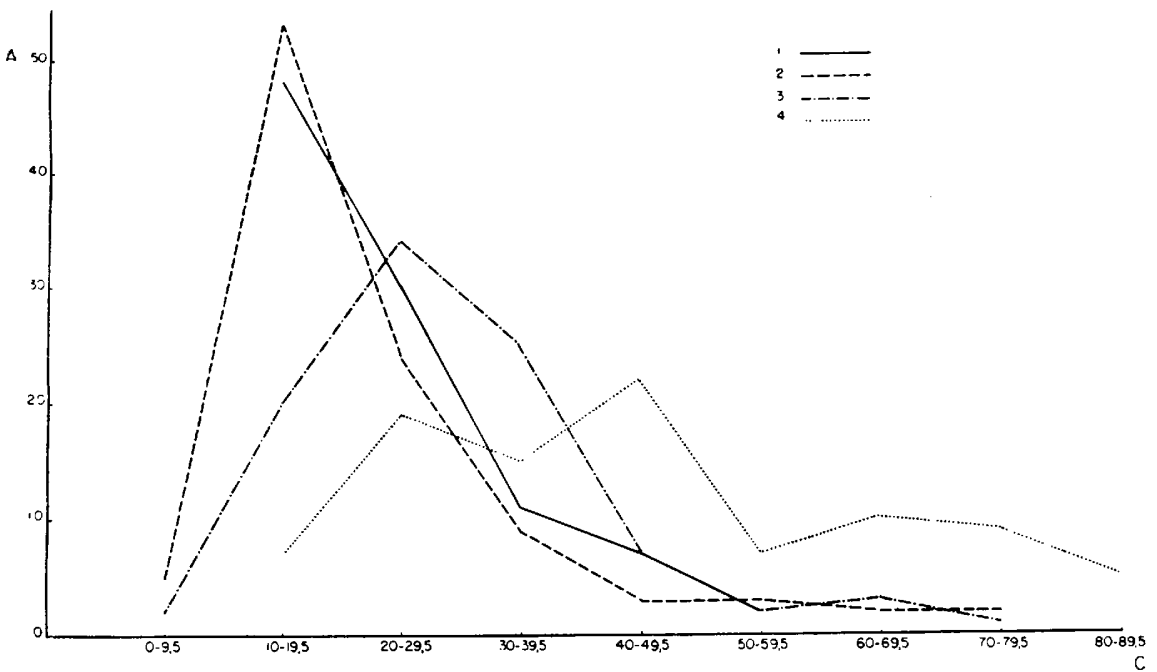

Gráfico 2 - Distribuição segundo a concentração de lotes de amostras analisadas para cada método. $\mathrm{A}=$ número de amostras; $\mathrm{C}=$ concentração $(\mathrm{mg} / 100 \mathrm{ml})$; 1 método de Bossak e col.; 2 - método de Denis e Ayer; 3 - método de Machebœuf e Rebeyrotte; 4 - método de Dittebrandt.

O desvio médio padrão encontrado para cada um dos métodos foi o seguinte: método de Bossak e col. 0,6123; método de Denis e Ayer 0,6728; método de Machebœuf e Rebeyrotte 2,3021; método de Dittebrandt 2,0918. 


\section{CONCLUSÕES}

Os registros da literatura acusam variações grandes da taxa normal de proteínas do LCR, as quais podem ser explicadas, pelo menos em parte, pela diversidade dos métodos empregados no seu estudo. Estes, nem sempre apresentam a fidelidade requerida para a análise de material pobre em proteínas como é o LCR.

Dos métodos analisados, o de Bossak e col. se mostrou satisfatório; os colorimétricos não preencheram os requisitos de fidelidade necessários para o estudo de pequenas concentrações protêicas pela grande influência do êrro instrumental efetivo verificada. Tal influência é pequena para o método de Denis e Ayer; entretanto, a somação desta influência do êrro instrumental com o efeito que sofre o método pela variação das taxas relativas de albumina e globulinas ${ }^{5}$, compromete sua precisão. O método de Dittebrandt, a par da grande influência do êrro instrumental, tem também contra si o fato de ser sensivel a substâncias nitrogenadas com três ou mais cadeias polipetídicas, em vista de usar o reativo do biureto ${ }^{3}$; embora a curva de calibração obtida pelo autor seja mais sensivel, não foi possível reproduzí-la, o que corrobora as observações de Riopel ${ }^{19}$ sôbre o perigo do emprêgo de précalibraçōes em espectrofotometria.

As verificações dêste estudo objetivam a necessidade de se ter em mente a importância do êrro instrumental efetivo sempre que se empregue espectrofotomètricamente um método de dosagem da proteinorraquia, pois a determinação precisa de taxas pequenas assume grande importância do ponto de vista clínico; aumentos discretos podem ocorrer precocemente em certas afecções neurológicas, servindo de elemento de orientação diagnóstica. Métodos que forneçam limites muito grandes para as variações normais não são úteis sob êsse ponto de vista. Já os grandes aumentos podem ser mais fàcilmente estudados e variações nesses niveis têm, do ponto de vista clínico, apenas valor especulativo.

Embora o presente estudo não reúna número de análises suficiente para Indicar uma média normal, os dados apresentados permitem uma orientação na escolha do método capaz de apresentar fidelidade suficiente para estabelecimento dessas médias normais. Assim, dos métodos analisados, foi o de Bossak e col. o que se mostrou mais satisfatório.

\section{RESUMO}

Tendo em vista as diferenças existentes entre as taxas consideradas normais pelos diversos autores para a proteinorraquia, foi feito um estudo para verificar até que ponto tais diferenças podem ser explicadas por condições de técnica.

Quatro métodos de determinação do conteúdo protêico total do líqüido cefalorraquidiano foram analisados — dois baseados em turbidimetria e dois em colorimetria - sendo utilizado o espectrofotometro Coleman Junior, modêlo 6-A. Os métodos turbidimétricos foram os de Bossak, Rosenberg e 
Harris e o de Denis e Ayer e os colorimétricos de Machebœuf e Rebeyrotte e de Dittebrandt. Para cada um foi preparada carta de calibração utilizando diluições cuidadosamente preparadas de misturas de líquores límpidos e incolores, nas quais fôra efetuada, prèviamente, a determinação do teor protêico pelo método de Kjeldahl.

Determinações da taxa protêica foram feitas em certo número de amostras (entre 80 e 100) para cada método, sendo as concentrações correspondentes calculadas mediante a carta de calibração estabelecida. O conteúdo protêico de cada uma delas tinha sido avaliado de modo aproximado pelo método de Nissl. Os dados obtidos mostraram a influência do êrro instrumental efetivo em relação às taxas pequenas, particularmente nos métodos colorimétricos, a qual foi acompanhada de elevação das respectivas médias dos valores de concentração. Esta elevação foi evidenciada também em uma série de 20 líquores cujo conteúdo protêico foi determinado concomitantemente pelos quatro métodos; a freqüência de distribuição de quatro séries de amostras, em zonas de concentração, para cada um dos métodos, mostrou um número maior em zonas correspondentes a teores protêicos mais elevados para aquêles métodos sujeitos a êrro instrumental efetivo maior.

Éstes dados vêm trazer um elemento para a compreensão das diferentes taxas consideradas normais na literatura, as quais variam, às vêzes, entre limites muito amplos. A determinação precisa assume grande importância quando encarada do ponto de vista clínico, principalmente quando se tem em vista o estudo dos aumentos discretos que podem ocorrer precocemente em certas afecções neurológicas, servindo de elemento de orientação diagnóstica.

\section{SUMMARY}

Critical study on some methods for the determination of protein content of the cerebrospinal fluid.

On the basis of the difference among values stated as normal by different authors to protein content of cerebrospinal fluid the present study was enterprised to verify whether these differences might be introduced by technical conditions. Four methods for protein determination were studied; two based on turbidimetric reactions and two on colorimetric ones. The first two were the trichloracetic acid method of Bossak, Rosenberg and Harris and the sulphosalycilic acid method of Denis and Ayer; the colorimetric methods were those of Dittebrandt (Weichselbaum biuret reagent) and of Machebœuf and Rebeyrotte (nitric acid reagent). The calibration was conducted in a Coleman Junior spectrophotometer model 6-A with carefully prepared dilutions of pools of cerebrospinal fluids clear and colourless whose protein content was previously determined by the Kjeldahl procedure.

Determination of protein content were made in several specimens of cerebrospinal fluid by each one of the methods and concentrations calculated through the calibration curves established. The protein content of all samples was previously evaluated by the Nissl method in an approximative way. The data obtained showed an influence of the effective instrument error on 
the normal taxes, specially on the colorimetric methods analised. This was accompanied by a rise in the mean values for each one. The data of twenty specimens whose protein content was estimated concomitantly by the four methods bring further evidence as to agree with this. The frequency of distribution in concentration zones of four series of specimens studied by each one of the methods showed a larger distribution in regions of higher protein concentration for methods with increased influence of effective instrument error.

The present data give a way to understand the different taxes supported as normal in the literature whose range is sometimes too much extent, bringing difficulty in the evaluation of slight increasings in protein content which bare importance in the early diagnosis of some neurological affections.

\section{BIBLIOGRAFIA}

1. ANDfA, E. D. - Liquido Céfalo-Raquideo. El Ateneo, Buenos Aires, 1946, pág. 107. 2. AYER, J. B.; DAILEY, M. E.; FREMONT-SMITH, F. - Denis Ayer method for the quantitative estimation of protein in the cerebrospinal fluid. Arch. Neurol. a. Psychiat., 26:1038 (novembro) 1931. 3. BAUER, H.; ANGELSTEIN, I. Zur Methodik der Gesamteiweissbestimmung im Liquor. Klin. Wschr., 30:277 (15, marco) 1952. 4. BONOLA, F. - La Rachicentesi ed il Liquido Cefalo-Rachidiano. L. Cappelli Ed., Bolonha, 1922, pág. 71. 5. BOSSAK, H. N.; ROSENBERG, A. A.; HARRIS, A. - A quantitative turbidimetric method for the determination of spinal fluid protein. J. Ven. Dis. Inform., 30:100 (abril) 1949. 6. CANTANI, F. - Il Liquido Cefalo-Rachidiano. Casa Ed. V. Idelson, Nápoles, 1931, pág. 65. 7. CIPRIANI, A.; BROPHY, D. - A method for determining cerebrospinal fluid protein by the photoelectric colorimeter. J. Lab. Clin. Med., 28:1269 (julho) 1943. 8. DEMME, H. - Die Liquordiagnosis in Klinik und Praxis. Ed. 2. Urban \& Schwarzenberg, München, 1950, pág. 39. 9. DITTEBRANDT, M. - Application of the Weichselbaum biuret reagent to the determination of spinal fluid protein. Am. J. Clin. Pathol., 18:439 (maio) 1948. 10. ESKUCHEN, K. - La Punción Lombar. Trad. espanhola, Calpe Ed., Madrid, 1921, pág. 54. 11. FIESSINGER, N.; OLIVIER, H. R.; HERBAIN, M. Diagnostics Biologiques et Fonctionels. Ed. 6, Libr. Maloine Ed., Paris, 1949, pág. 743. 12. HARDING, V. L.; HARRIS, A. - The effect of temperature variants on quantitative turbidimetric determinations of spinal fluid protein using trichloracetic acid. J. Ven. Dis. Inform., 30:325 (novembro) 1949. 13. HILLER, A.; PLAZIN, J.; van SLYKE, D. D. - A study of conditions for Kjeldahl determination of nitrogen in proteins. J. Biol. Chem., 176:1401, -948. 14. KAFKA, V. - Die Zerebrospinalfluessigkeit. Franz Deuticke Ed., Leipzig, 1930, págs. 42-49. 15. LANGE, O. - O Líqüido Céfalo-Raquidiano em Clinica. Cia. Melhoramentos de São Paulo, São Paulo, 1937, pág. 51. 16. LEVINSON, A. - Cerebrospinal Fluid in Health and in Disease, ed. 3. Henry Knipton Ed., Londres, 1929, pág. 118. 17. MERRITT, H. H.; FREMONT-SMITH, F. - The Cerebrospinal Fluid. W. B. Saunders Co., Filadélfia, 1937, págs. 29 e 257. 18. MESTREZAT, W. - Le Liquide Céphalo-Rachidien Normal et Pathologique. A. Maloine Ed., Paris, 1912, págs. 10-15, 165. 19. RIOPEL, P. - Que penser des precalibrations en photocolorimetrie. L'Union Méd. du Canada, 80:1064 (setembro) 1951. (Resumo in Abstr. Bioanal. Technol., 1:62, junho, 1953). 20. SANDMANN, F. Vergleichende Liquoreiweissbestimmungen mit der Methode von Gleiss und Hinsberg. Münch. med. Wschr., 94:567 (21, março) 1952. 21. WAWERSICK, F.; BOEKLER, H. J. - Über Elektrophotometrische Bestimmung des Liquoreiweisses. Klin. Wschr., 29: 552, 1951. 22. WIKOFF, H. L.; KAZDAN, P. - A critique of methods for the determination of protein in cerebrospinal fluid. Amer. J. Clin. Pathol., 21:1173 (dezembro) 1951.

Clinica Neurológica. Hospital das Clínicas da Fac. Med. da Univ. de São Paulo Caixa Postal 3461 - Säo Paulo, Brasil. 